\title{
Human tenocytes are stimulated to proliferate by acetylcholine through an EGFR signalling pathway
}

\author{
Gloria Fong • Ludvig J. Backman • Gustav Andersson • \\ Alexander Scott $\cdot$ Patrik Danielson
}

Received: 5 July 2012 / Accepted: 7 November 2012 / Published online: 5 December 2012

(C) The Author(s) 2012. This article is published with open access at SpringerLink.com

\begin{abstract}
Studies of human patellar and Achilles tendons have shown that primary tendon fibroblasts (tenocytes) not only have the capacity to produce acetylcholine (ACh) but also express muscarinic $\mathrm{ACh}$ receptors (mAChRs) through which ACh can exert its effects. In patients with tendinopathy (chronic tendon pain) with tendinosis, the tendon tissue is characterised by hypercellularity and angiogenesis, both of which might be influenced by ACh. In this study, we have tested the hypothesis that ACh increases the proliferation rate of tenocytes through $\mathrm{mAChR}$ stimulation and have examined whether this mechanism operates via the extracellular activation of the epidermal growth factor receptor (EGFR), as shown in other fibroblastic cells. By use of primary human tendon cell cultures, we identified cells
\end{abstract}

This work was primarily supported by a grant from the National Swedish Research Council (521-2009-2921 to P.D.). The project was additionally supported by grants from the Swedish National Centre for Research in Sports (54/10 and P2011-0170 to P.D.), the Swedish

Society of Medicine (SLS-176511 to P.D.), the Magn. Bergvall Foundation (to P.D.), the Tore Nilsson Foundation for Medical Research (to P.D.), a Umeå University Young Researcher Award (to P.D.) and a Michael Smith Scholar award (to A.S.).

The authors declare no conflicts of interest.

G. Fong $\cdot$ L. J. Backman • G. Andersson • P. Danielson $(\bowtie)$

Department of Integrative Medical Biology, Anatomy,

Umeå University, SE-901 87 Umeå, Sweden

e-mail: patrik.danielson@anatomy.umu.se

G. Fong $\cdot$ A. Scott

Department of Physical Therapy, University of British Columbia,

Vancouver, BC, Canada

G. Fong $\cdot$ A. Scott

Centre for Hip Health and Mobility, Vancouver Coastal Health and

Research Institute, Vancouver, BC, Canada

L. J. Backman

Department of Surgical and Perioperative Sciences, Sports

Medicine, Umeå University, Umeå, Sweden expressing vimentin, tenomodulin and scleraxis and found that these cells also contained enzymes related to $\mathrm{ACh}$ synthesis and release (choline acetyltransferase and vesicular acetylcholine transporter). The cells furthermore expressed mAChRs of several subtypes. Exogenously administered ACh stimulated proliferation and increased the viability of tenocytes in vitro. When the cells were exposed to atropine (an mAChR antagonist) or the EGFR inhibitor AG1478, the proliferative effect of ACh decreased. Western blot revealed increased phosphorylation, after ACh stimulation, for both EGFR and the extracellular-signal-regulated kinases 1 and 2. Given that tenocytes have been shown to produce $\mathrm{ACh}$ and express mAChRs, this study provides evidence of a possible autocrine loop that might contribute to the hypercellularity seen in tendinosis tendon tissue.

Keywords Muscarinic acetylcholine receptors .

Tendinopathy - Tendinosis · Choline acetyltransferase .

Vesicular acetylcholine transporter $\cdot$ Atropine $\cdot$ Non-neuronal acetylcholine $\cdot$ Human

\section{Introduction}

In recent years, increasing attention has been devoted to the non-neuronal expression of signal substances traditionally associated with neurons and the potential roles of such substances in various pathological conditions. Particular interest has been given to acetylcholine (ACh; Wessler et al. 2001), a classical neurotransmitter well-known as being localised in the central and peripheral nervous systems. Contemporary research has demonstrated that ACh and/or its synthesising enzyme, choline acetyltransferase (ChAT), are present in non-neuronal human cells, such as the epithelium of the airways and epidermis, endothelial and muscle cells and various immune cells (Wessler et al. 2001; 
Kawashima and Fujii 2003). A physiological role of nonneuronal ACh might explain the widespread presence of ACh receptors, such as muscarinic receptors (mAChRs), in tissues not innervated by cholinergic neurons (Wessler et al. 1998). Recently, we have demonstrated that mAChRs of subtype $M_{2}\left(M_{2} R s\right)$ are expressed in blood vessels, nerves and primary fibroblastic cells (tenocytes) in both Achilles (Bjur et al. 2008) and patellar (Danielson et al. 2006) tendons of man, whereas cholinergic innervation is scarce or absent. The $\mathrm{M}_{2} \mathrm{Rs}$ are particularly abundant in tendons afflicted by tendinosis (Danielson et al. 2006, 2007; Bjur et al. 2008). Tendinosis frequently underlies tendinopathy, a clinical condition defined by chronic tendon pain and impaired function, and is characterised by a series of histopathological tissue changes (Khan et al. 1999), including tenocyte proliferation and angiogenesis. The above observations have led to the hypothesis that $\mathrm{ACh}$ plays a role in the development of tendinosis, since the stimulation of ACh receptors in other tissues has previously been shown to stimulate angiogenesis (Jacobi et al. 2002), modulate peripheral nociception (Vogelsang et al. 1995; Wess et al. 2003) and promote the proliferation of liver myofibroblasts (Oben et al. 2003). Furthermore, tenocytes in vivo have been shown to produce a variety of signal substances traditionally associated with neurons, especially in tendinosis (for a review, see Danielson 2009). A striking finding in this regard is the suggested increased production and release of $\mathrm{ACh}$ in tendinosis tissue, as evidenced by a higher expression of ChAT and the vesicular ACh transporter (VAChT) in tenocytes (Danielson et al. 2006, 2007; Bjur et al. 2008).

As is well-known, G-protein coupled receptors (GPCRs), to which mAChRs belong, can transduce mitogenic signals leading to proliferation (New and Wong 2007) and evidence has suggested that an ACh stimulus can result in the proliferation of fibroblast-like cells via these receptors (Matthiesen et al. 2006, 2007). In fibroblasts, proliferation is typically mediated by classical mitogen-activated protein kinases (MAPK), namely extracellular-signal-regulated kinases 1 and 2 (ERK1/ 2; Matthiesen et al. 2007). As has also been shown in a variety of cell types, the stimulation of GPCR can result in the transactivation of the epidermal growth factor receptor (EGFR), leading to the activation of ERK1/2 (New and Wong 2007; Xie et al. 2009). In some cells, the GPCR-EGFR transmission appears to be independent of extracellular ligands (relying on cytoplasmic mechanisms), whereas in other cell types, cellsurface-bound pro-ligands are processed and released to the extracellular matrix by metalloproteinases (MMPs; Kraus et al. 2003; Rozengurt 2007). These ligands subsequently bind to and stimulate the EGFR.

The role that mAChRs might play in the modulation of human tendon cell behaviour is unknown. Furthermore, whether primary Achilles tendon cell cultures maintain their expression of mAChRs in vitro or retain their capacity for ACh production is also unknown. Therefore, in this study, we have examined the presence of $\mathrm{mAChRs}$ and the expression of the synthesising enzyme ChAT and of VAChT in primary Achilles tendon cell cultures. Moreover, given that tenocyte proliferation is a prominent and early feature of tendinosis and that the effect of ACh on tenocyte proliferation has not previously been studied, we have also examined the possible proliferative effect of ACh on tenocytes and its mechanism of action.

\section{Materials and methods}

Ethics statement

These studies were approved by the Regional Ethical Review Board in Umea and were performed according to the principles of the Declaration of Helsinki. Written informed consent was received from all participants.

\section{Human tendon cell culture}

Biopsies were isolated and cultured as previously described (Backman et al. 2011). Briefly, tendon tissue biopsies from the lateral mid-portion of the Achilles tendon of healthy donors were enzymatically digested and the cells were cultured in D-MEM supplemented with $10 \%$ fetal bovine serum (FBS; Invitrogen, Grand Island, N.Y., USA; code no. 16000), 1\% pen-strep (Invitrogen; code no. 15140) and $0.2 \% \mathrm{~L}$-glutamine (Invitrogen; code no. 25030 ) at $37^{\circ} \mathrm{C}$ in a humidified atmosphere of $5 \% \mathrm{CO}_{2}$.

\section{Experimental conditions}

The cells used in this study were in passages 3-6 to ensure a similar phenotype. All experiments were performed under serum-starved condition of $1 \%$, a condition in which the cells had a healthy appearance and a steady proliferation rate. The serum-starved condition was initiated $24 \mathrm{~h}$ before the start of an experiment.

\section{Cell-signalling experiments}

The cells were seeded in cell culture plates (BD Bioscience; BD Falcon, Bedford, Mass., USA; code no. 353004) at a density of 275,000 cells/plate and incubated under serumstarved conditions as described under "Experimental conditions". The cells were then pre-treated with either the EGFR inhibitor, AG1478 $(0.8 \mu \mathrm{M}$; Calbiochem, Darmstadt, Germany; code no. 658548), the metalloproteinase inhibitor, GM6001 ( $8 \mu \mathrm{M}$; Calbiochem; code no. 364206) or the muscarinic receptor antagonist, atropine 
$\left(10^{-5} \mathrm{M}\right.$; Sigma, Saint Louis, Mo., USA; code no. A0132) for $30 \mathrm{~min}$. Following this, the cells were stimulated with ACh $\left(10^{-6} \mathrm{M}\right.$; Sigma; code no. A2661) or the vehicle (dimethylsuphoxide) for an additional $30 \mathrm{~min}$. A further control without treatment was also included. To determine the levels of phosphorylated (phospho-)ERK1/2 and phospho-EGFR, Western blot analysis was performed (for details, see below).

\section{Immunocytochemistry}

Antibodies directed towards ChAT (1:50; Chemico, Temecula, Calif., USA; code no AB144P), $\mathrm{M}_{2} \mathrm{R}$ (1:100; Chemico; code no. AB5166), $\mathrm{M}_{3} \mathrm{R}$ (1:50; Novus Biologiocals, Littleton, Colo., USA; code no. NLS5259), $\mathrm{M}_{4} \mathrm{R}$ (1:50; Novus Biologiocals; code no. NLS220), $\mathrm{M}_{5} \mathrm{R}$ (1:50; Novus Biologiocals; code no. NLS1334), VAChT (1:25; Santa Cruz, Calif., USA; code no. sc-7716), tenomodulin (1:100; Santa Cruz; code no. sc-49325), vimentin (1:100; Dako, Glostrup, Denmark; code no. M0725), collagen I (1:100; Abcam, Cambridge, UK; code no. ab34710), collagen III (1:100; Abcam; code no. ab7778), scleraxis (1:25; Abcam; code no. ab58655), alpha-smooth muscle actin (1:100; Abcam; code no. ab5694) or connexin 43 (1:25; Santa Cruz; code no. sc-59949) were used. Cells $\left(1.5 \times 10^{4} /\right.$ well $)$ were seeded on 8-well chamber slides (BD Falcon; code no. 354118) and allowed to adhere overnight before being fixed for $5 \mathrm{~min}$ in $2 \%$ paraformaldehyde in $0.1 \mathrm{M}$ phosphate buffer (pH7.4) and subsequently washed four times in phosphate-buffered saline (PBS) before being blocked in swine (for primary polyclonal antibodies raised in rabbit, i.e., the antibodies towards $\mathrm{M}_{2} \mathrm{R}, \mathrm{M}_{3} \mathrm{R}, \mathrm{M}_{4} \mathrm{R}, \mathrm{M}_{5} \mathrm{R}$, alphasmooth muscle actin, scleraxis, collagen I and collagen III), donkey (for polyclonal goat-antibodies, i.e., antibodies towards ChAT, VAChT and tenomodulin) or rabbit (for the monoclonal mouse-antibody towards connexin 43) serum for $15 \mathrm{~min}$. This was followed by incubation with the primary antibody for $60 \mathrm{~min}$ at $37^{\circ} \mathrm{C}$ or at $4^{\circ} \mathrm{C}$ overnight. After being washed four times, an additional blocking step was performed before incubation with the secondary antibody, a tetramethylrhodamine isothiocyanate (TRITC)-conjugated swine anti-rabbit IgG (Dako; Copenhagen, Denmark; code no. R0156), fluorescein isothiocyanate (FITC)-conjugated donkey anti-goat IgG (Jackson Immunoresearch; West Grove, Pa., USA; code no. 705-095-147) or a TRITC-conjugated rabbit anti-mouse (Dako; code no. R0270) for $30 \mathrm{~min}$ at $37^{\circ} \mathrm{C}$. When double-staining with vimentin or tenomodulin was carried out, incubation with the secondary antibody was followed by four washes in PBS before a blocking step in normal rabbit or donkey serum for $15 \mathrm{~min}$. The primary antibody was incubated with the cells for $60 \mathrm{~min}$ at $37^{\circ} \mathrm{C}$, followed by an additional four washes in PBS and a blocking step in normal (rabbit, donkey) serum for 15 min. After incubation with the secondary antibody, namely a TRITC-conjugated rabbit anti-mouse IgG (Dako; code no. R0270) or FITC-conjugated donkey anti-goat IgG (Jackson Immunoresearch; code no. 705-095-147), the cells were washed four times in PBS and mounted with Vectashield Hard Set Medium with 4,6-diamidino-2-phenylindole (DAPI; Vector Laboratories; Burlingame, Calif., USA; code no. H-1500).

Expression of $M_{4} R$ in tenocytes was also confirmed on tissue sections from biopsies of normal healthy tendon tissue by using immunohistochemistry according to a previously used protocol (Bjur et al. 2008).

Control staining was performed by the substitution of the primary antibody with PBS. A Zeiss Axioskop 2 Plus microscope equipped for epifluorescence and an Olympus DP70 digital camera was used for analysis.

\section{Western blot}

Cells were lysed in a buffer consisting of $150 \mathrm{mM}$ sodium chloride, $1 \%$ Triton, $0.5 \%$ sodium deoxycholate, $0.1 \%$ sodium dodecyl sulphate (SDS), $50 \mathrm{mM}$ TRIS, pH8.0, freshly supplemented with a protease inhibitor cocktail at a dilution of 1:200 (Sigma; code no. P1860). Protein concentration was determined by using the Protein Assay Dye Reagent Concentrate (Bio-Rad, Hercules, Calif., USA; code no. 500-0006) with bovine serum albumin (BSA; Sigma; code no. A9647) as a standard. Total protein $(20-40 \mu \mathrm{g})$ from each sample or the $\mathrm{M}_{2} \mathrm{R}$ peptide, used as a positive control (Chemico; code no. Ab5166), was diluted in a Laemmli sample buffer (Bio-Rad; code no. 161-0737) and boiled for 5 min before being loaded and separated on an SDSpolyacrylamide gel and then transferred to a polyvinylidene difluoride membrane (Santa Cruz; code no. sc-3723). Ponceau $\mathrm{S}$ staining $(0.1 \%$ Ponceau red, $1 \%$ acetic acid diluted in MilliQ water) confirmed successful transfer before the staining procedure. Membranes were blocked in 5\% non-fat milk at room temperature for $1 \mathrm{~h}$ before incubation with the primary antibodies. The antibody towards phospho-ERK1/ 2 (Thr202, Tyr204) was used at a dilution of 1:2000 (Cell signal, Danvers, Mass., USA; code no. 4370). According to the manufacturer, this antibody does not cross-react with the phosphorylation residues of JNK/SAPK or p38 MAP kinases. The antibody towards phospho-EGFR was used at a dilution of 1:1000 (Cell signal; code no. 3777) and, according to the manufacturer, it might weakly cross-react with other tyrosine-phosphorylated proteins. The antibody towards $\mathrm{M}_{2} \mathrm{R}$, which is reported by the manufacturer not to exhibit any cross-reactivity with other muscarinic receptors, was used at a dilution of 1:1000 (Chemico; code no. AB5166). The antibody towards $M_{4} R$ was used at a dilution of 1:500 (Santa Cruz; code no. sc-9109), the antibody towards scleraxis at a dilution of 1:1000 (Abcam; code no. 

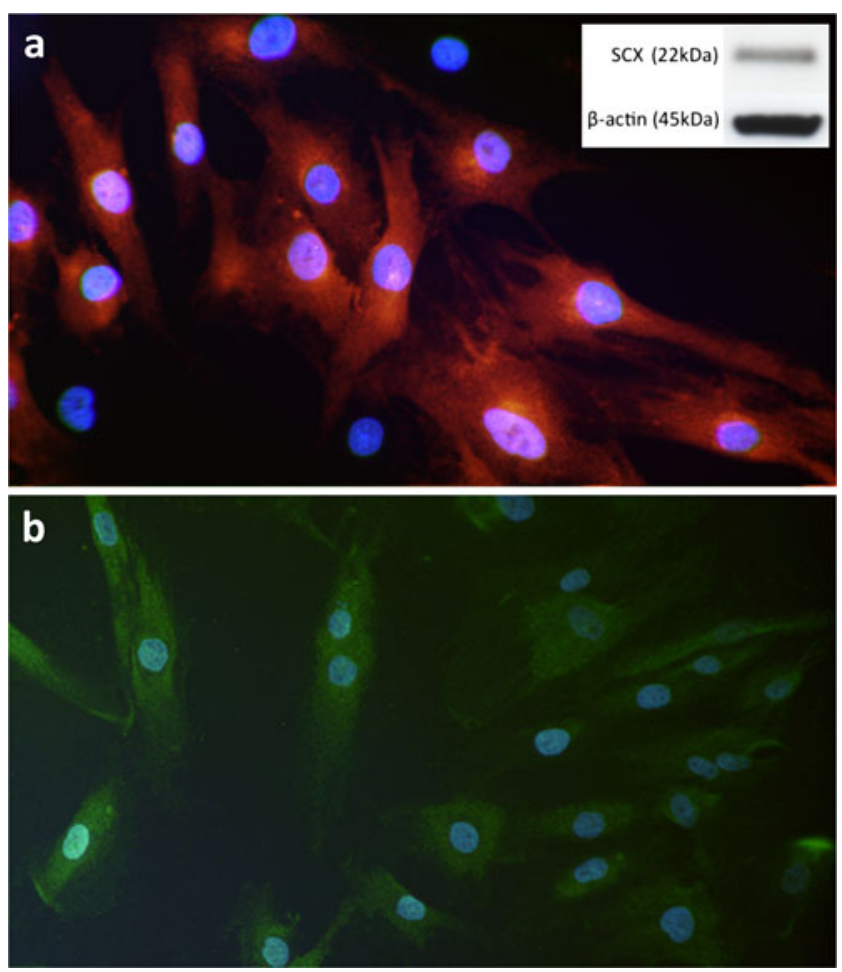

Fig. 1 Immunocytochemical staining of primary cultures of human Achilles tendon cells. Nuclei are stained with 4,6-diamidino-2-phenylindole (DAPI; blue). a Most cells are positive for scleraxis (red, tetramethylrhodamine isothiocyanate [TRITC]), a key regulator of tenocyte differentiation. Inset Western blot showing a positive band for scleraxis corresponding to the predicted size of $22 \mathrm{kDa} ; \beta$-actin is shown as a reference. $\mathbf{b}$ Cells showing immunoreaction for tenomodulin (green, fluorescein isothiocyanate [FITC]), a glycoprotein predominantly expressed in tendons and ligaments. x235 (a) and x185 (b)

ab58655) and the antibody towards beta ( $\beta$ )-actin at a dilution of 1:2000 (Cell Signal; code no. 4967). All primary antibodies were raised in rabbit and immunostaining was
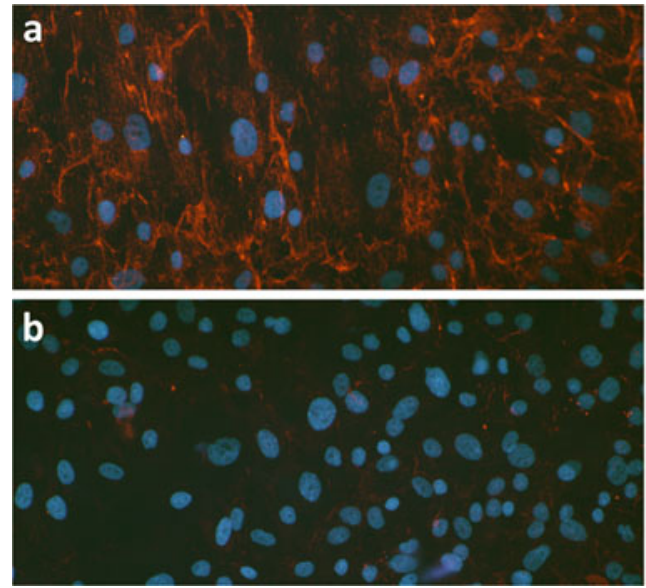

Fig. 2 Immunocytochemical staining (red, TRITC) of primary cultures of human Achilles tendon cells with surrounding extracellular matrix components. Immunofluorescence for collagen I (a) shows that this protein is abundantly expressed in the cultures, whereas, as expected, collagen III (b) is only sparsely performed overnight at $4^{\circ} \mathrm{C}$. The membranes were then washed and incubated with horseradish peroxidase (HRP)conjugated goat anti-rabbit secondary antibody, at a dilution of 1:2000 (Cell Signal; code no. 7074) for $1 \mathrm{~h}$ at room temperature. Band detection was performed by using chemiluminescent HRP substrate (GE Healthcare, Little Chalfont, Buckinghamshire, UK; code no. RPN2132) for 5 min prior to visualisation on high performance chemiluminescence film (GE Healthcare; code no. 28-9068-38).

To confirm equal protein loading, the membranes were stripped with a Western blot stripping buffer (Thermo Scientific, Rockford, Ill., USA; code no. 21059) and re-probed for $\beta$-actin expression.

\section{Cell viability}

Crystal violet dye was used to measure cell viability as previously described (Backman et al. 2011). Briefly, $1.5 \times 10^{5}$ cells/well were seeded in a 6 -well plate and allowed to adhere overnight before serum starvation. Cells were washed in PBS to remove non-adherent cells prior to fixation in $1 \%$ glutaraldehyde for $30 \mathrm{~min}$. After additional washes in PBS, the adherent cells were stained with $0.1 \%$ crystal violet (Sigma; code no. C3886), washed in water, airdried and then permeabilised in 30\% methanol and $10 \%$ acetic acid. The absorbance was read at $590 \mathrm{~nm}$ in a 96well plate format. Experiments were performed in triplicate.

\section{Cell proliferation assay with 5-bromo-2'-deoxy-uridine}

The manufacturer's instructions were followed (Roche Applied Science, Mannheim, Germany; code no. 11299964001). Briefly, $1.5 \times 10^{4}$ cells/well on an 8 -well chamber slide (BD
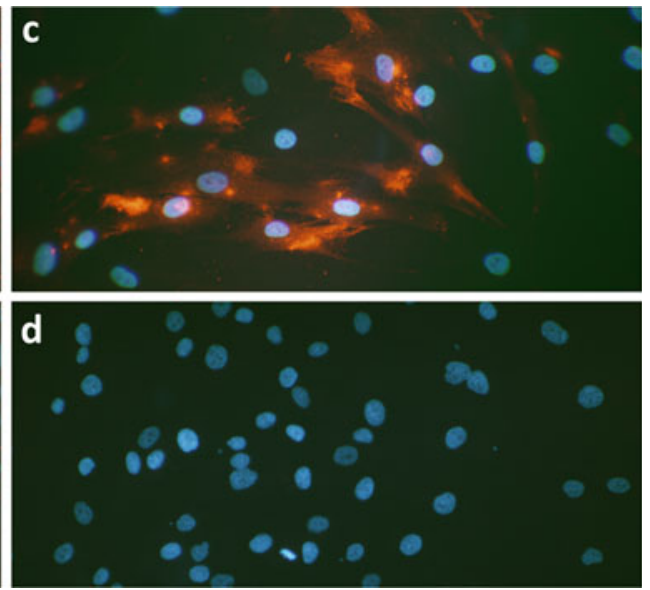

seen. The cells additionally show positive immunoreaction for connexin 43 (c), a gap junction protein known to be present in networks of tendon cells in vivo. The cells are negatively stained for alpha-smooth muscle actin (d). Nuclei are stained with DAPI (blue). $\times 120$ 
Falcon; code no. 354118) were pre-labelled with 5-bromo-2'deoxy-uridine $(\mathrm{BrdU})$ for $120 \mathrm{~min}$ at $37^{\circ} \mathrm{C}$ in a humidified atmosphere of $5 \% \mathrm{CO}_{2}$. This was followed by fixation in a fixative solution ( $250 \mathrm{mM}$ glycine, $100 \mathrm{ml}$ ethanol, $\mathrm{pH} 2.0$ ) for $20 \mathrm{~min}$ at $20^{\circ} \mathrm{C}$. Following fixation, the cells were covered with a monoclonal $\mathrm{BrdU}$ antibody for $30 \mathrm{~min}$ at $37^{\circ} \mathrm{C}$, before being incubated with anti-mouse-Ig towards alkaline phosphate for an additional $30 \mathrm{~min}$ at $37^{\circ} \mathrm{C}$. Finally, the cells were covered in $4.3 \mathrm{mM}$ nitroblue tetrazolium and $3.3 \mathrm{mM}$ 5-bromo-4-chloro-3-indolyl-phosphate diluted in substrate solution (100 mM TRIS-HCl, $100 \mathrm{mM} \mathrm{NaCl}, 50 \mathrm{mM} \mathrm{MgCl} 2, \mathrm{pH} 9.5)$ and then mounted in Vectashield HardSet Medium with DAPI (Vector Laboratories; code no. H-1500). The percentage of BrdU-positive cells was determined. Experiments were performed in triplicate.

Reverse transcription with quantitative polymerase chain reaction

As previously described (Backman et al. 2011), total RNA was isolated by using an RNeasy kit (Qiagen, Hilden, Germany; code no. 74106) and then $1 \mu \mathrm{g}$ of this RNA was reversed-transcribed into cDNA by using a High

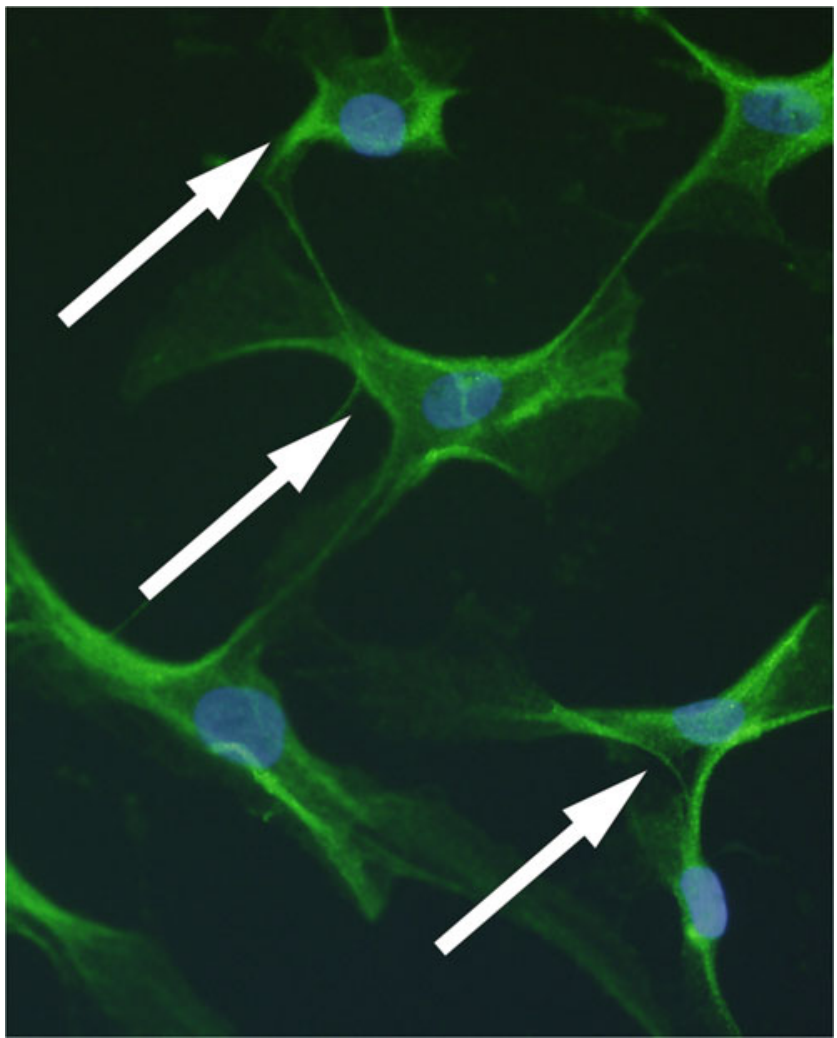

Fig. 3 Cultured human Achilles tendon cells immunopositive (green, FITC; some marked with arrows) for the acetylcholine (ACh)-synthesising enzyme choline acetyltransferase (ChAT). DAPI staining demonstrates nuclei (blue). $\times 390$
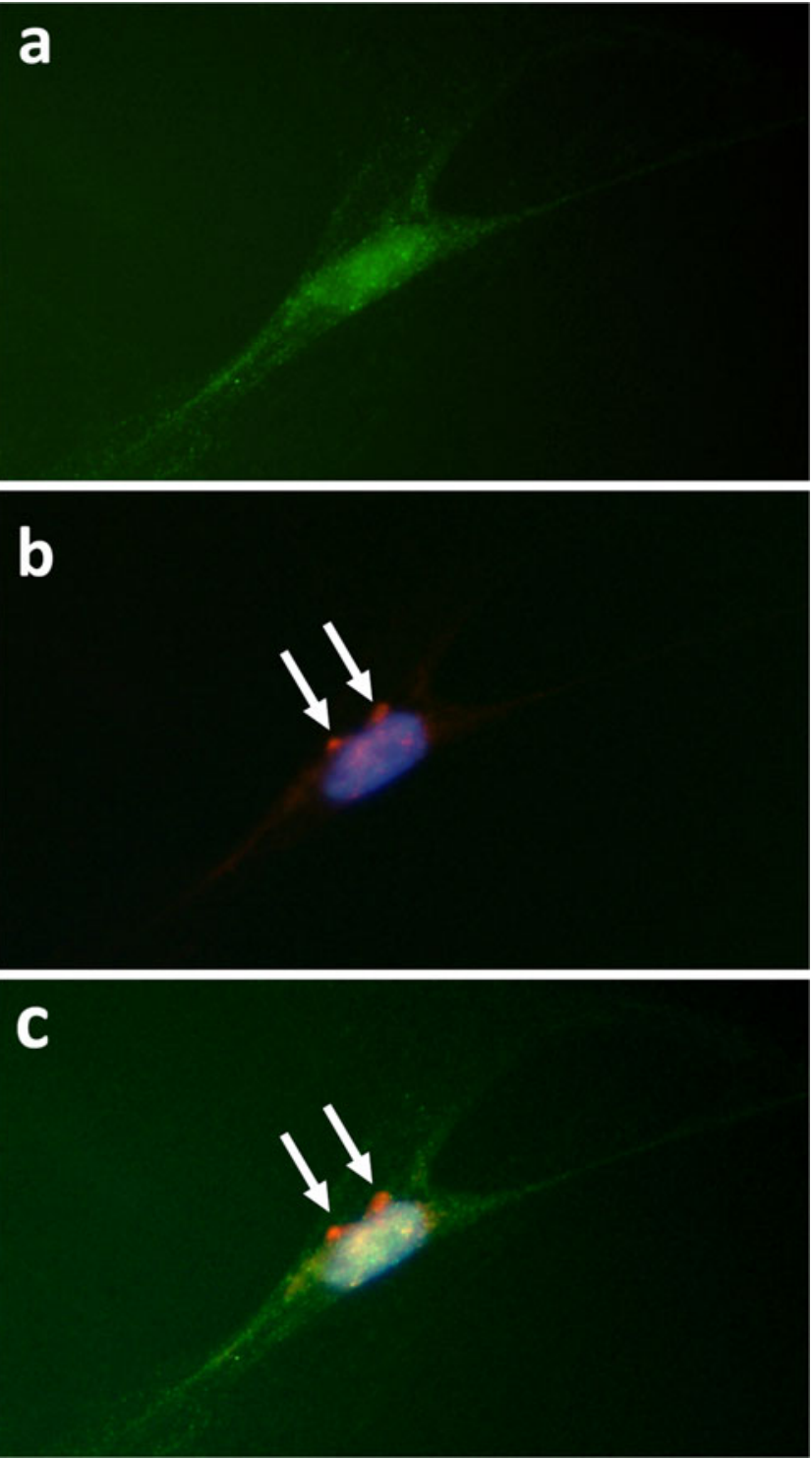

Fig. 4 Cultured human Achilles tenocyte visualised by using immunocytochemistry. a The cell is immunopositive for the AChsynthesising enzyme ChAT (green, FITC). b The same cell stained with DAPI to demonstrate the nucleus (blue) and immunolabelled for $\mathrm{M}_{2} \mathrm{R}$ (red, TRITC; arrows). $\mathbf{c}$ Digitally merged image of $\mathbf{a}$ and $\mathbf{b} . \times 570$

Capacity cDNA Reverse Transcription kit (Applied Biosystems $[\mathrm{ABI}]$, Warrington, Cheshire, UK; code no. 4368813). Quantitative polymerase chain reaction (qPCR) was performed by using a TaqMan fast universal

\section{$\mathrm{M}_{2} \mathrm{R}(80 \mathrm{kDa})$ \\ Beta-actin (45kDa) a

$$
\begin{array}{r}
\mathrm{M}_{4} \mathrm{R}(74 \mathrm{kDa}) \\
\text { Beta-actin }(45 \mathrm{kDa})
\end{array}
$$$$
\text { b }
$$

Fig. 5 Western blots for $M_{2} R$ (a) and $M_{4} R$ (b) on cultured and lysed human primary Achilles tendon cells. Immunopositive bands are present at the expected molecular weights. $\beta$-Actin is shown as a reference. 
PCR master mix (ABI; code no. 4352042) and probes for $\mathrm{M}_{2} \mathrm{R}$ (ABI; code no. Hs00265208), $\mathrm{M}_{3} \mathrm{R}$ (ABI; code no. Hs00265216), $\mathrm{M}_{4} \mathrm{R}$ (ABI; code no. Hs00265219), $\mathrm{M}_{5} \mathrm{R}$ ( $\mathrm{ABI}$; code no. Hs00255278) and scleraxis (ABI; code no. Hs03054634). Each sample, run in duplicate, contained the probe $(20 \times)$, master mix $(2 \times), 20 \mathrm{ng}$ sample and nuclease-free water to give a final volume of $10 \mu \mathrm{l}$ for each reaction. Amplification was conducted under the following conditions: after $20 \mathrm{~s}$ of denaturation at $95^{\circ} \mathrm{C}$, the amplification was carried out for $1 \mathrm{~s}$ at $95^{\circ} \mathrm{C}$ for denaturation and $20 \mathrm{~s}$ at $60^{\circ} \mathrm{C}$ for annealing/extension in an ViiA7 instrument. The expression level was determined relative to the endogenous control, $\beta$-actin (ABI; code no. 4333762F).

\section{Statistics}

Data were statistically analysed by using PASW Statistics 18 (18.0.0; SPSS, Chicago, Ill., USA). One-way analysis of variance (ANOVA), followed by the Bonferroni post-hoc test, was applied. All results were successfully reproduced at least once. Significance was predetermined at $P<0.05$.

\section{Results}

Phenotyping of cells

The vast majority of cells in the primary cultures were immunopositive for vimentin, scleraxis (Fig. 1a) and tenomodulin (Fig. 1b) in the passages and serum concentrations used for experiments, thereby indicating a fibroblastic phenotype (tenocytes), as previously described for this model (Backman et al. 2011). The presence of scleraxis protein was also confirmed by using Western blot (Fig. 1a, inset) and the presence of scleraxis mRNA was confirmed by qPCR. Production of collagen I and also an extremely low expression of collagen III were further found (Fig. 2a, b). In addition, cells with myofibroblastic characteristics could also be excluded, as all cultured cells were negative for alpha-smooth muscle actin staining in the passages and serum concentrations used for the experiments (Fig. 2d). Cells were positively immunostained for connexin 43 (Fig. 2c). Connexin 43 is the main gap junction protein expected to be found in tendon cells and is known to create functional linkages among networks of tendon cells in vivo (McNeilly et al. 1996).

ChAT, VAChT and muscarinic receptor expression in cultured tendon cells

Most of the cultured human tendon cells were found to express clear immunoreactivity for ChAT (Figs. 3, 4a) and VAChT. For the muscarinic receptors, positive immunoreaction on cells was seen for all the studied receptors, including, as previously reported for tenocytes in tissue sections (Danielson et al. 2006, 2007; Bjur et al. 2008), $\mathrm{M}_{2} \mathrm{R}$ (Fig. 4b) and, in particular, $\mathrm{M}_{4} \mathrm{R}$, which was expressed in a majority of the cells. In many cases, the same cells expressed both enzymes related to the synthesis/release of

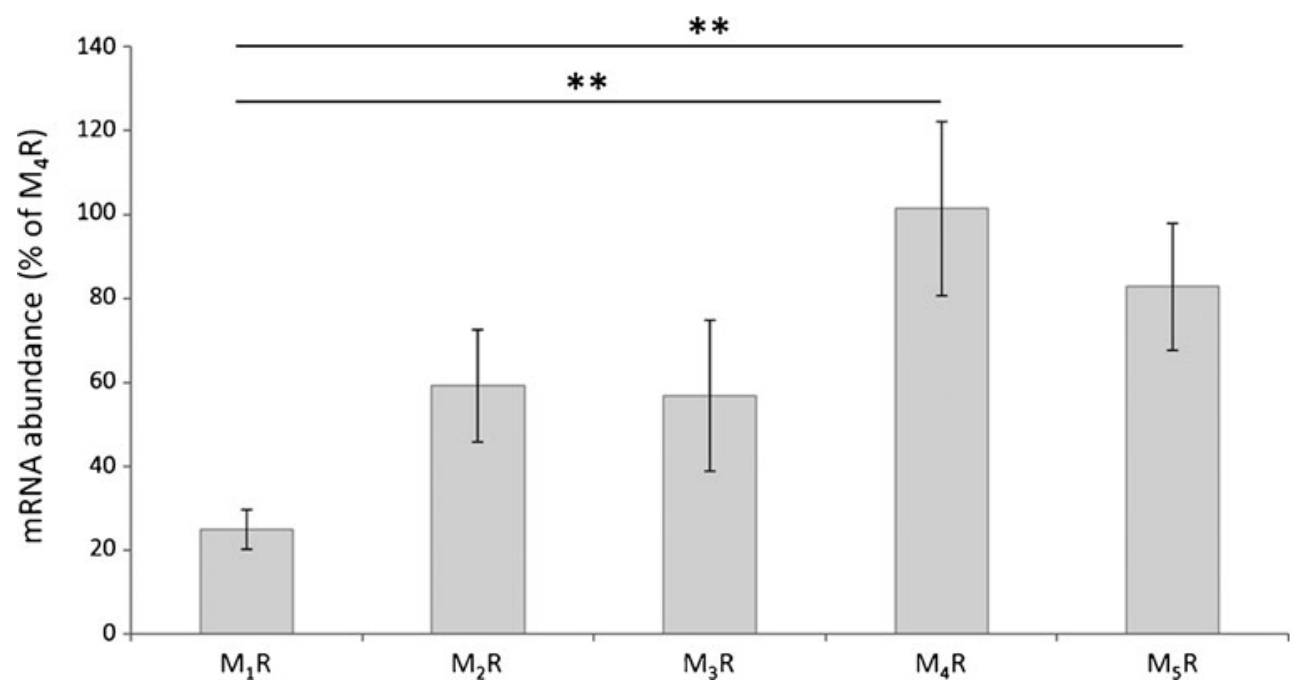

Fig. 6 Quantitative polymerase chain reaction (qPCR) was used to study the presence of mRNA for various muscarinic receptor subtypes. The abundance of mRNA for the various subtypes was compared with that of $M_{4} R$, which was set to $100 \%$. The results show that mRNA for all the studied subtypes is present. The expression of $M_{1} R$ mRNA is significantly lower than that of

$\mathrm{M}_{4} \mathrm{R}$ and $\mathrm{M}_{5} \mathrm{R}$ mRNA. The differences in expression between $\mathrm{M}_{2} \mathrm{R}$ and $\mathrm{M}_{4} \mathrm{R}$ mRNA $(P=0.07)$ and between $\mathrm{M}_{3} \mathrm{R}$ and $\mathrm{M}_{4} \mathrm{R}$ mRNA $(P=0.05)$ were close to significant (error bars standard deviation). ${ }^{* *} P \leq 0.01$. One-way analysis of variance (ANOVA) with the Bonferroni post hoc test, based on triplicates in the experiment 
$\mathrm{ACh}$ and the muscarinic receptors (e.g. Fig. 4c). The presence of $\mathrm{M}_{4} \mathrm{R}$ on human tenocytes in tissue sections was confirmed by immunohistochemistry.

Given earlier results that $\mathrm{M}_{2} \mathrm{R}$ expression was found in human tenocytes in tissue sections (Danielson et al. 2006, 2007; Bjur et al. 2008) and that $\mathrm{M}_{4} \mathrm{R}$ was the subtype with the highest expression in tendon cell cultures, Western blots were performed for these two subtypes to confirm their presence. Western blots for $\mathrm{M}_{2} \mathrm{R}$ displayed one major band at $80 \mathrm{kDa}$ in lysates of cultured tendon cells (Fig. 5a). These results were in accordance with results from a positive control of purified $\mathrm{M}_{2} \mathrm{R}$ protein (not shown). Western blots for $\mathrm{M}_{4} \mathrm{R}$ displayed a band at $74 \mathrm{kDa}$ corresponding to the expected size (Fig. 5b).

Expression of $M_{1} R, M_{2} R, M_{3} R, M_{4} R$ and $M_{5} R$ mRNA was also confirmed to be present in the cells by qPCR (Fig. 6). $M_{1} R$ mRNA was expressed at a significantly lower level than both $\mathrm{M}_{4} \mathrm{R}(P \leq 0.01)$ and $\mathrm{M}_{5} \mathrm{R}(P \leq 0.01)$ mRNA. A trend for the higher expression of $\mathrm{M}_{4} \mathrm{R}$ mRNA was also noted in comparison with both $\mathrm{M}_{2} \mathrm{R}(P=0.07)$ and $\mathrm{M}_{3} \mathrm{R}$ $(P=0.05)$ mRNA.

\section{Effects of ACh}

Exogenously administered ACh significantly increased the number of viable tendon cells after $36 \mathrm{~h}$ of incubation as seen by crystal violet staining $(P<0.01$; one-way ANOVA with the Bonferroni post-hoc test) and this effect was effectively blocked by simultaneous incubation with the muscarinic $\mathrm{ACh}$ receptor antagonist atropine (Fig. 7).

The percentage of proliferating (BrdU-positive) tendon cells in cultures after incubation with ACh was significantly increased (doubled) after $24 \mathrm{~h}$ compared with the controls $(P<0.01)$ but also with cells incubated with atropine $(P<0.05)$ or the EGFR-blocker AG1478 $(P<0.05$; Fig. 8; one-way ANOVA with the Bonferroni post-hoc test).

Western blot analysis revealed that the administration of ACh resulted in the phosphorylation (i.e. activation) of both EGFR and ERK1/2 in the cultured cells. This activation peaked after 20-30 min for EGFR and after 30-45 min for ERK1/2 (Fig. 9a).

The ERK1/2 phosphorylation induced by incubation with ACh was effectively blocked in the presence of the muscarinic receptor antagonist, atropine (Fig. 9b). In addition, inhibition of either EGFR or MMP with their specific blockers (AG1478 and GM6001, respectively) decreased the phosphorylation of ERK1/2 (Fig. 9b).

\section{Discussion}

The present study shows that human Achilles tenocytes express enzymes related to ACh synthesis/release (ChAT and

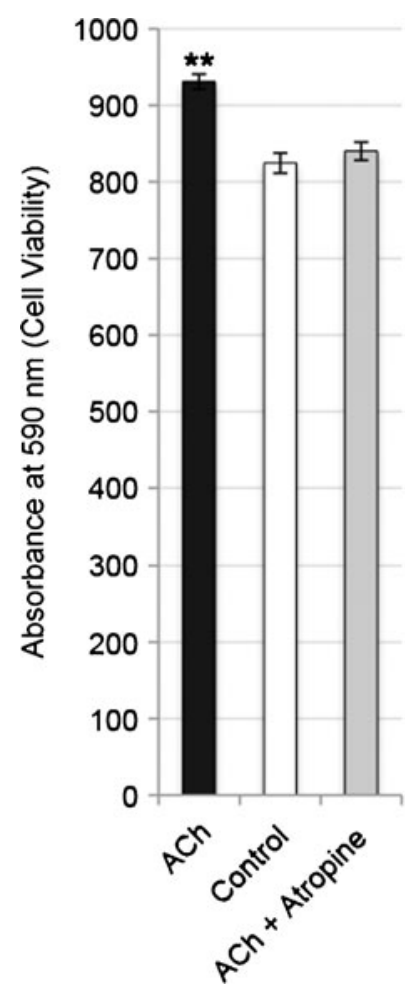

Fig. 7 Analysis of viable tendon cells in human primary cultures after $36 \mathrm{~h}$ of incubation with $10^{-6} \mathrm{M}$ acetylcholine $(A C h)$, without $\mathrm{ACh}$ (Control) and with $\mathrm{ACh}$ and the muscarinic $\mathrm{ACh}$ receptor blocker atropine $\left(A C h+\right.$ Atropine; the concentration of atropine being $10^{-5}$ M) measured by absorbance $(590 \mathrm{~nm})$ of crystal violet staining. The significant increase in viable cells seen after incubation with $\mathrm{ACh}$ is effectively blocked with atropine. Cells were seeded at a density of $1.5 \times 10^{5}$ cells/well in 6-well plates (error bars standard deviation). ${ }^{* *} P<0.01$ for $\mathrm{ACh}$ against both Control and $\mathrm{ACh}+$ Atropine. Oneway ANOVA with the Bonferroni post hoc test, based on triplicates in the experiment

VAChT) and mAChRs in vitro, findings previously shown for these cells in vivo, especially in tendinosis (Danielson et al. 2006, 2007; Bjur et al. 2008). Furthermore, we demonstrate that these cells are encouraged, when exposed to $\mathrm{ACh}$, to proliferate via $\mathrm{mAChR}$ stimulation and subsequently the activation of EGFR and ERK1/2.

Previous reports have shown that the effects of $\mathrm{mAChR}$ activation include fibroblast proliferation (Matthiesen et al. 2006; Profita et al. 2009), mediated through the activation of the ERK1/2 pathway (Matthiesen et al. 2007). Other studies have shown that the stimulation of these receptors on fibroblasts increases collagen synthesis in the lungs (Haag et al. 2008) as a part of tissue remodelling in response to chronic inflammation (Jeffery 2001). In human Achilles tenocytes, we have, in the present study, observed that, after $24 \mathrm{~h}$, the number of cells in the S-phase of the cell cycle (BrdUpositive) is significantly higher in the ACh-exposed cells and also that, after an additional $12 \mathrm{~h}$, the number of viable cells is significantly increased as a result. Collagen synthesis has not been quantified in this study but this would surely be 


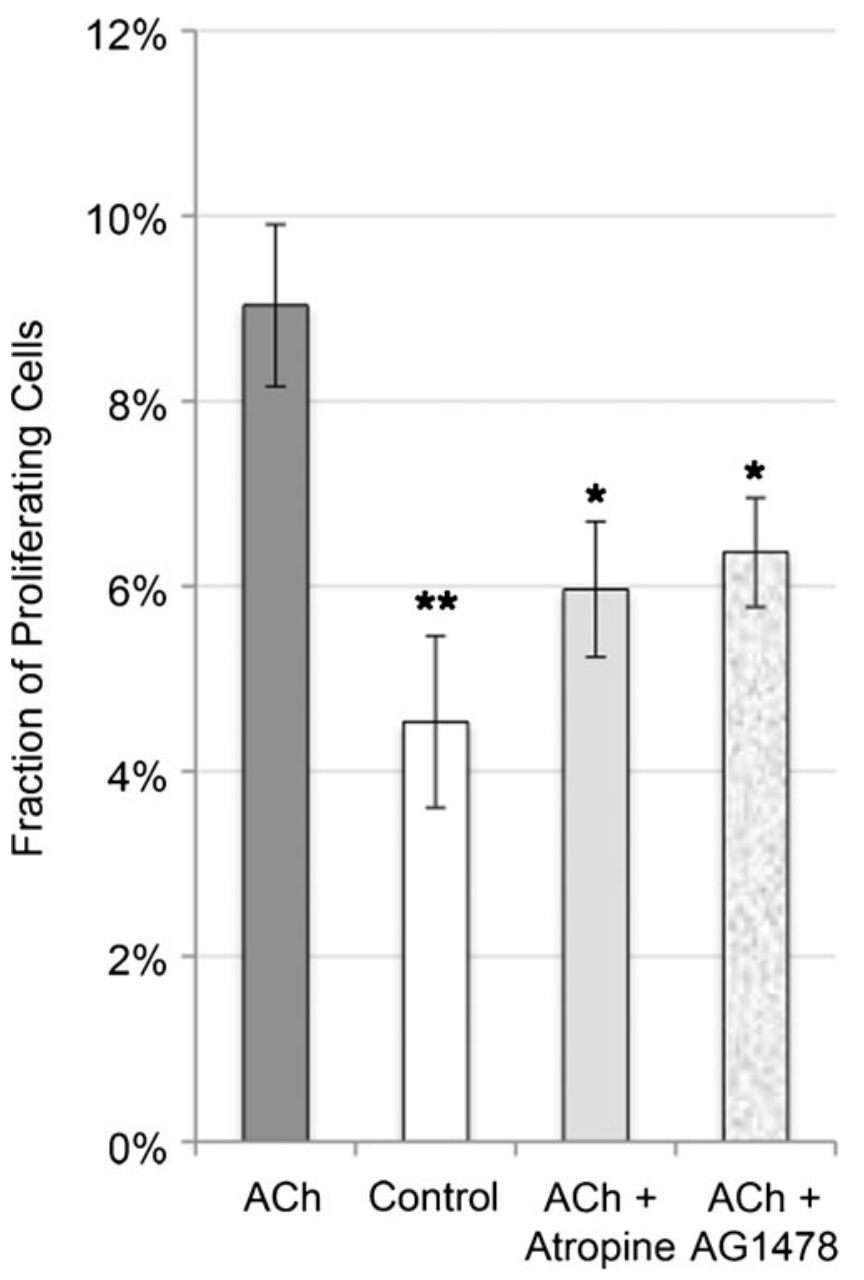

Fig. 8 Mean fraction of proliferating (BrdU-positive) tendon cells in human primary cultures after $24 \mathrm{~h}$ of incubation with ACh $\left(10^{-6} \mathrm{M}\right)$, without ACh (Control), with ACh and the muscarinic receptor inhibitor atropine $\left(10^{-5} \mathrm{M}\right)$ and with $\mathrm{ACh}$ and the epidermal growth factor receptor (EGFR) inhibitor AG1478 $(0.8 \mu \mathrm{M})$. A statistically significant increase can be seen in the percentage of proliferating cells after incubation with ACh compared with the control $(* * P<0.01)$ and compared with incubation with the inhibitors $(* P<0.05)$. No significant difference can be found between the treatments with atropine and AG1478 or between either of the inhibitors and the control. Cells were seeded at a density of $1.5 \times 10^{4}$ cells/well in 8 -well chamber slides (error bars standard deviation). One-way ANOVA test with the Bonferroni post hoc test, based on triplicates in the experiment

an interesting next step, as tendinosis is characterised by increased collagen type III content, which is also seen in the early stages of tendon healing (Maffulli et al. 2000).

The cultured tendon cells of the present model have been shown to retain a fibroblastic phenotype in the early passages used for the experiments here, by the immunofluorescence for vimentin (typical of mesechyme-derived cells, such as fibroblasts; Rufai et al. 1992) and tenomodulin (a specific marker for tenocytes; Docheva et al. 2005; Jelinsky et al. 2010), a finding confirmed in an earlier study of our model (Backman et al. 2011). Tenomodulin is a type II transmembrane glycoprotein that is highly expressed in

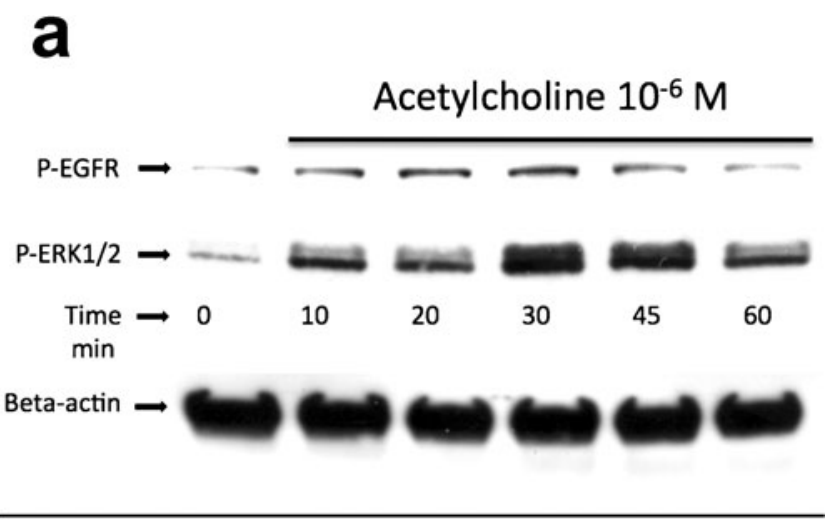

b

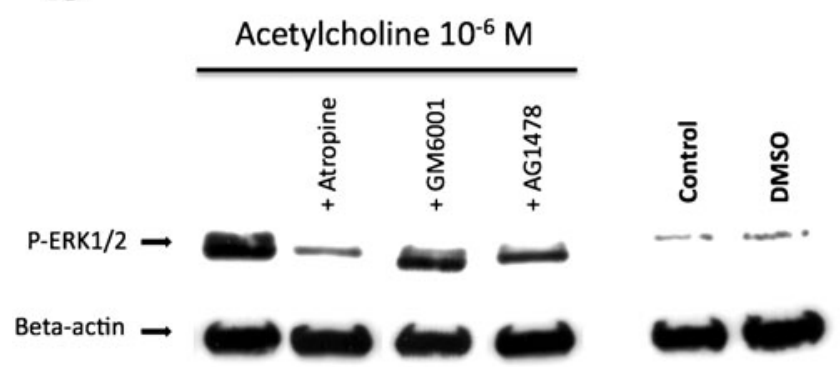

Fig. 9 a Western blot showing phosphorylated EGFR $(P-E G F R)$ and extracellular-signal-regulated kinases 1 and $2(P$-ERK1/2) in cultured human Achilles tendon cells at various time points after incubation with ACh $\left(10^{-6} \mathrm{M}\right)$. Exposure to ACh resulted in phosphorylation (i.e. activation) of both EGFR and ERK1/2 in the cultured cells; this activation peaked after 20-30 $\mathrm{min}$ for EGFR and 30-45 $\mathrm{min}$ for ERK1/2. $\beta$-Actin is shown as a reference. b Western blot showing phosphorylated ERK1/2 (P-ERK1/2) in cultured human Achilles tendon cells after $45 \mathrm{~min}$ of incubation in pure ACh $\left(10^{-6} \mathrm{M}\right)$, ACh and the muscarinic $\mathrm{ACh}$ receptor antagonist atropine (+Atropine), $\mathrm{ACh}$ and a metalloproteinase (MMP) antagonist $(+$ GM6001), ACh and an EGFR antagonist $(+A G 1478)$, regular media (Control) or dimethylsuphoxide $(D M S O)$. ERK1/2 activation by ACh is effectively blocked when incubated simultaneously with atropine. Moreover, inhibition of either EGFR or MMP reduces the phosphorylation of ERK1/2. $\beta$-Actin is shown as a reference

tendons and ligaments and it has been reported to be positively regulated by scleraxis, which is a transcription factor that also regulates the expression of type I collagen, thus being a key transcription factor in tenocyte differentiation (Shukunami et al. 2006; Lejard et al. 2007; Jelinsky et al. 2010). Scleraxis has been observed at both the protein and the mRNA levels in the cells of this study. The proliferative effect of ACh on these fibroblastic cells has been found to be mAChR-dependent and to lead to EGFR and ERK1/2 activation. An overview of the proposed pathway is presented in Fig. 10.

The specific MMP responsible for cleaving the proligand to a mature EGFR ligand has not been defined in this study. However, we have observed a tendency towards decreased ERK1/2 phosphorylation in response to the broad-spectrum MMP inhibitor GM6001, which has 


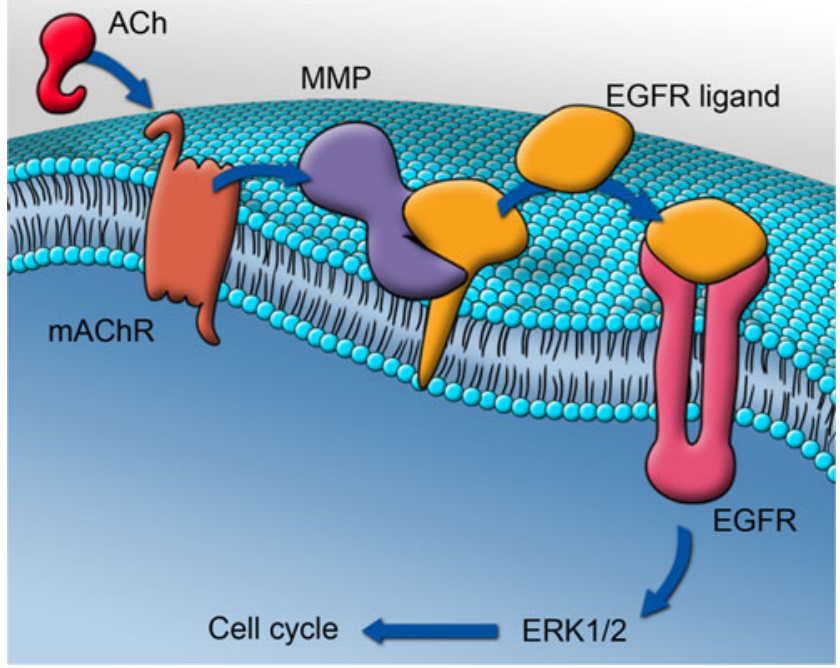

Fig. 10 Representation of the proposed cellular pathways involved in the acetylcholine $(A C h)$-induced proliferation of human tendon cells. ACh stimulates membrane-bound muscarinic ACh receptors $(m A C h R)$ that in turn activate matrix metalloproteinases $(M M P)$ to cleave a cellsurface-associated epidermal growth factor receptor ligand $(E G F R$ ligand). The ligand then binds to EGFR, which in turn increases cell proliferation through the phosphorylation of the mitogen-activated protein kinases, extracellular-signal-regulated kinases 1 and 2 (ERK1/ 2 ). The results of the present study identify a potential role for each of these steps (see Figs. 8, 9). Artwork by G. Andersson

MMP- 1 as its primary target and MMP-2, $-3,-8$ and -9 as secondary targets. The finding that the inhibitory effect is not more dramatic might be attributable to the involvement of other MMPs that are not affected by GM6001. For example, in colon cancer cells, Xie et al. (2009) have shown that $\mathrm{ACh}$ induces proliferation involving MMP-1, MMP-7 and MMP-10, in turn, leading to EGFR activation, which can be abolished with the muscarinic inhibitor atropine and that the stimulation of MMP-7 mimics the actions of ACh. Another possible agent is the tumor necrosis factor alpha $\left(\mathrm{TNF}_{\alpha}\right)$-converting enzyme (TACE or ADAM17). This enzyme is known to cleave $\mathrm{TNF}_{\alpha}$ but has also been found to be the only metalloprotinease that efficiently cleaves transforming growth factor-alpha $\left(\mathrm{TGF}_{\alpha}\right)$, another EGFR ligand (Hinkle et al. 2003). GPCR stimulation in colonocytes leads to the cleavage and release of the mature $\mathrm{TGF}_{\alpha}$, which binds to, and phosphorylates, EGFR (Koon et al. 2004).

The targeting of mAChRs is frequently used in the clinical setting to abolish unwanted effects of $\mathrm{ACh}$ and mAChRs have been proposed as potential targets in several diseases, such as chronic obstructive pulmonary disease in which the inhibition of $\mathrm{mAChRs}$ can delay the decline in lung function (Vincken et al. 2002; Anzueto et al. 2005). The mAChR family can be divided into the "odd-numbered" and the "even-numbered" receptors. The "even-numbered" receptors $M_{2} R$ and $M_{4} R$ couple via $G_{i}$ and $G_{o} \alpha$ subunits (Caulfield and Birdsall 1998). In lung fibroblasts,
$\mathrm{M}_{2} \mathrm{R}$ has been found to be the most prominent $\mathrm{mAChR}$ and the regulation of fibroblast proliferative rate has been shown to correlate best with modulation via $\mathrm{M}_{2} \mathrm{R}$ (Matthiesen et al. 2006). In this study, we have confirmed the presence of $\mathrm{M}_{2} \mathrm{R}$ protein and mRNA in cultured human tenocytes, findings previously shown for tenocytes in tissue sections from both patellar (Danielson et al. 2006) and Achilles (Bjur et al. 2008) tendons in man. However, the expression of the other known mAChRs has not previously been examined in human tendons. In this study, we have also investigated $M_{3} R$, $M_{4} R$ and $M_{5} R$, with $M_{4} R$ clearly being the most abundantly expressed receptor in the in vitro setting. The expression of $\mathrm{M}_{4} \mathrm{R}$ has, in the present study, also been confirmed for tenocytes in tissue sections. This study has not investigated the possible expression or role of nicotinic ACh receptors, which is a drawback. Nevertheless, since the proliferative effect of ACh in this study is abolished with atropine, we have confirmed that proliferation takes place preferably through muscarinic stimulation and not nicotinic receptor stimulation.

The verification of $\mathrm{ACh}$ production by human tenocytes is based on the expression of ChAT and VAChT and not on a measurement of the ACh molecule itself. This is of course a limitation of this study, although, as has been repeatedly reported, the expression of ChAT and VAChT is correlated to ACh production. ChAT catalyses the synthesis of ACh from choline and acetyl-CoA (Tuček 1982, 1988) and VAChT is known then to shuttle ACh to vesicles in the nerve terminal (Eiden 1998). Over-expression of VAChT is related to an increased ACh release (Prado et al. 2002). All in all, the present study supports the existence of a cholinergic autocrine loop in tenocytes (Forsgren et al. 2009a, 2009b), ACh produced by the cells themselves being able to stimulate the proliferation of the same cells through the activation of the ERK1/2 system via binding to the mAChRs on the cell surface. The potential relevance of this phenomenon to tendinosis is evident, given that hypercellularity is such a prominent feature in the histopathology, both at early and late stages (Khan et al. 1999). Nevertheless, other possible targets of the ACh produced by tenocytes in tendon tissue might be receptors found in blood vessel walls or on sensory nerve fascicles (Danielson et al. 2006; Bjur et al. 2008). These receptor sites are also of interest, since ACh has well-known vascular and pain-modulating effects (Vogelsang et al. 1995; Dussor et al. 2004), tendinosis also being characterised by vascular changes and chronic pain (Khan et al. 1999; Alfredson and Ohberg 2005; Cook et al. 2005).

In summary, based on the results of the present study and on those of our previous investigations (Danielson et al. 2006, 2007; Bjur et al. 2008), we propose the following. Human tenocytes, harbouring the capability to produce $\mathrm{ACh}$, increase this production during tendinosis 
development. Via an autocrine loop, the ACh produced by tenocytes stimulates $\mathrm{mAChRs}$ on the cell surface, which in their turn increase ERK1/2 phosphorylation through the activation of EGFR and contribute to the increased cell proliferation (Fig. 10) and the tenocyte hypercellularity seen in tendinosis. In an early stage of tendinosis, hypercellularity might be a part of a healing or adaptive response but, in the chronic stage, excessive tenocyte proliferation could be detrimental to tendon structure and function. The nonneuronal cholinergic system of tendon tissue is thus a possible target for future modulation of these processes in tendinosis.

Acknowledgments The authors thank Mr. Filip Löfgren for technical services and Dr. Arthur V. Sampaio for much valued scientific advice. Professor Per-Arne Oldenborg and Assistant Professor Liu Jingxia are acknowledged for joint investments in laboratory facilities. The authors finally extend their deepest appreciation to Professor Håkan Alfredson for surgically providing the tissue material and to Mrs. Lotta Alfredson for coordinating donations.

Open Access This article is distributed under the terms of the Creative Commons Attribution License which permits any use, distribution, and reproduction in any medium, provided the original author (s) and the source are credited.

\section{References}

Alfredson H, Ohberg L (2005) Neovascularisation in chronic painful patellar tendinosis - promising results after sclerosing neovessels outside the tendon challenge the need for surgery. Knee Surg Sports Traumatol Arthrosc 13:74-80

Anzueto A, Tashkin D, Menjoge S, Kesten S (2005) One-year analysis of longitudinal changes in spirometry in patients with COPD receiving tiotropium. Pulm Pharmacol Ther 18:75-81

Backman LJ, Fong G, Andersson G, Scott A, Danielson P (2011) Substance $\mathrm{P}$ is a mechanoresponsive, autocrine regulator of human tenocyte proliferation. PLoS One 6:e27209

Bjur D, Danielson P, Alfredson H, Forsgren S (2008) Presence of a non-neuronal cholinergic system and occurrence of up- and down-regulation in expression of M2 muscarinic acetylcholine receptors: new aspects of importance regarding Achilles tendon tendinosis (tendinopathy). Cell Tissue Res 331:385-400

Caulfield MP, Birdsall NJ (1998) International union of pharmacology. XVII. Classification of muscarinic acetylcholine receptors. Pharmacol Rev 50:279-290

Cook JL, Malliaras P, De Luca J, Ptasznik R, Morris M (2005) Vascularity and pain in the patellar tendon of adult jumping athletes: a 5 month longitudinal study. Br J Sports Med 39:458-461

Danielson P (2009) Reviving the "biochemical" hypothesis for tendinopathy: new findings suggest the involvement of locally produced signal substances. Br J Sports Med 43:265-268

Danielson P, Alfredson H, Forsgren S (2006) Immunohistochemical and histochemical findings favoring the occurrence of autocrine/paracrine as well as nerve-related cholinergic effects in chronic painful patellar tendon tendinosis. Microsc Res Tech 69:808-819

Danielson P, Andersson G, Alfredson H, Forsgren S (2007) Extensive expression of markers for acetylcholine synthesis and of M2 receptors in tenocytes in therapy-resistant chronic painful patellar tendon tendinosis - a pilot study. Life Sci 80:2235-2238

Docheva D, Hunziker EB, Fassler R, Brandau O (2005) Tenomodulin is necessary for tenocyte proliferation and tendon maturation. Mol Cell Biol 25:699-705

Dussor GO, Helesic G, Hargreaves KM, Flores CM (2004) Cholinergic modulation of nociceptive responses in vivo and neuropeptide release in vitro at the level of the primary sensory neuron. Pain 107:22-32

Eiden LE (1998) The cholinergic gene locus. J Neurochem 70:22272240

Forsgren S, Alfredson H, Bjur D, Rantapaa-Dahlqvist S, Norrgard O, Dalen T, Danielson P (2009a) Novel information on the nonneuronal cholinergic system in orthopedics provides new possible treatment strategies for inflammatory and degenerative diseases. Orthop Rev (Pavia) 1:e11

Forsgren S, Grimsholm O, Jonsson M, Alfredson H, Danielson P (2009b) New insight into the non-neuronal cholinergic system via studies on chronically painful tendons and inflammatory situations. Life Sci 84:865-870

Haag S, Matthiesen S, Juergens UR, Racke K (2008) Muscarinic receptors mediate stimulation of collagen synthesis in human lung fibroblasts. Eur Respir J 32:555-562

Hinkle CL, Mohan MJ, Lin P, Yeung N, Rasmussen F, Milla ME, Moss ML (2003) Multiple metalloproteinases process protransforming growth factor-alpha (proTGF-alpha). Biochem 42:2127-2136

Jacobi J, Jang JJ, Sundram U, Dayoub H, Fajardo LF, Cooke JP (2002) Nicotine accelerates angiogenesis and wound healing in genetically diabetic mice. Am J Pathol 161:97-104

Jeffery PK (2001) Remodeling in asthma and chronic obstructive lung disease. Am J Respir Crit Care Med 164:S28-S38

Jelinsky SA, Archambault J, Li L, Seeherman H (2010) Tendonselective genes identified from rat and human musculoskeletal tissues. J Orthop Res 28:289-297

Kawashima K, Fujii T (2003) The lymphocytic cholinergic system and its contribution to the regulation of immune activity. Life Sci 74:675-696

Khan KM, Cook JL, Bonar F, Harcourt P, Astrom M (1999) Histopathology of common tendinopathies. Update and implications for clinical management. Sports Med 27:393-408

Koon HW, Zhao D, Na X, Moyer MP, Pothoulakis C (2004) Metalloproteinases and transforming growth factor-alpha mediate substance P-induced mitogen-activated protein kinase activation and proliferation in human colonocytes. J Biol Chem 279:4551945527

Kraus S, Benard O, Naor Z, Seger R (2003) c-Src is activated by the epidermal growth factor receptor in a pathway that mediates JNK and ERK activation by gonadotropin-releasing hormone in COS7 cells. J Biol Chem 278:32618-32630

Lejard V, Brideau G, Blais F, Salingcarnboriboon R, Wagner G, Roehrl MH, Noda M, Duprez D, Houillier P, Rossert J (2007) Scleraxis and NFATc regulate the expression of the pro-alpha1(I) collagen gene in tendon fibroblasts. J Biol Chem 282:17665-17675

Maffulli N, Ewen SW, Waterston SW, Reaper J, Barrass V (2000) Tenocytes from ruptured and tendinopathic Achilles tendons produce greater quantities of type III collagen than tenocytes from normal Achilles tendons. An in vitro model of human tendon healing. Am J Sports Med 28:499-505

Matthiesen S, Bahulayan A, Kempkens S, Haag S, Fuhrmann M, Stichnote C, Juergens UR, Racke K (2006) Muscarinic receptors mediate stimulation of human lung fibroblast proliferation. Am J Respir Cell Mol Biol 35:621-627

Matthiesen S, Bahulayan A, Holz O, Racke K (2007) MAPK pathway mediates muscarinic receptor-induced human lung fibroblast proliferation. Life Sci 80:2259-2262 
McNeilly CM, Banes AJ, Benjamin M, Ralphs JR (1996) Tendon cells in vivo form a three dimensional network of cell processes linked by gap junctions. J Anat 189:593-600

New DC, Wong YH (2007) Molecular mechanisms mediating the G protein-coupled receptor regulation of cell cycle progression. $\mathrm{J}$ Mol Signal 2:2

Oben JA, Yang S, Lin H, Ono M, Diehl AM (2003) Acetylcholine promotes the proliferation and collagen gene expression of myofibroblastic hepatic stellate cells. Biochem Biophys Res Commun 300:172-177

Prado MA, Reis RA, Prado VF, Mello MC de, Gomez MV, Mello FG de (2002) Regulation of acetylcholine synthesis and storage. Neurochem Int 41:291-299

Profita M, Bonanno A, Siena L, Bruno A, Ferraro M, Montalbano AM, Albano GD, Riccobono L, Casarosa P, Pieper MP, Gjomarkaj M (2009) Smoke, choline acetyltransferase, muscarinic receptors, and fibroblast proliferation in chronic obstructive pulmonary disease. J Pharmacol Exp Ther 329:753-763

Rozengurt E (2007) Mitogenic signaling pathways induced by G protein-coupled receptors. J Cell Physiol 213:589-602

Rufai A, Benjamin M, Ralphs JR (1992) Development and ageing of phenotypically distinct fibrocartilages associated with the rat Achilles tendon. Anat Embryol 186:611-618

Shukunami C, Takimoto A, Oro M, Hiraki Y (2006) Scleraxis positively regulates the expression of tenomodulin, a differentiation marker of tenocytes. Dev Biol 298:234-247
Tuček S (1982) The synthesis of acetylcholine in skeletal muscles of the rat. J Physiol (Lond) 322:53-69

Tuček S (1988) Choline acetyltransferase and the synthesis of acetylcholine. In: Whittaker VP (ed) Handbook of experimental pharmacology, vol 86. The cholinergic synapse. Springer, Berlin, pp 125-165

Vincken W, Noord JA van, Greefhorst AP, Bantje TA, Kesten S, Korducki L, Cornelissen PJ (2002) Improved health outcomes in patients with COPD during 1 year's treatment with tiotropium. Eur Respir J 19:209-216

Vogelsang M, Heyer G, Hornstein OP (1995) Acetylcholine induces different cutaneous sensations in atopic and non-atopic subjects. Acta Derm Venereol 75:434-436

Wess J, Duttaroy A, Gomeza J, Zhang W, Yamada M, Felder CC, Bernardini N, Reeh PW (2003) Muscarinic receptor subtypes mediating central and peripheral antinociception studied with muscarinic receptor knockout mice: a review. Life Sci 72:2047-2054

Wessler I, Kirkpatrick CJ, Racke K (1998) Non-neuronal acetylcholine, a locally acting molecule, widely distributed in biological systems: expression and function in humans. Pharmacol Ther 77:59-79

Wessler I, Kilbinger H, Bittinger F, Kirkpatrick CJ (2001) The biological role of non-neuronal acetylcholine in plants and humans. Jpn J Pharmacol 85:2-10

Xie G, Cheng K, Shant J, Raufman JP (2009) Acetylcholine-induced activation of M3 muscarinic receptors stimulates robust matrix metalloproteinase gene expression in human colon cancer cells. Am J Physiol Gastrointest Liver Physiol 296:G755-G763 